\title{
Waste water treatment plants as redistributors of resistance genes in bacteria
}

\author{
M. Gómez ${ }^{1}$, M. T. Díaz ${ }^{1}$, M. Araujo ${ }^{2}$, R. Sueiro ${ }^{2}$ \& J. Garrido ${ }^{2}$ \\ ${ }^{1}$ Labaqua S.A., Santiago de Compostela, Spain \\ ${ }^{2}$ Lab. Microbiology (Instituto de Investigación y Análisis Alimentarios), \\ Universidad de Santiago de Compostela, Spain
}

\begin{abstract}
The aim of this study was to assess the number of both extended-spectrum $\beta$-lactamases (ESBL) producing Enterobacteriaceae and vancomycin-resistant enterococci (VRE) present in the inflow (hospital and urban sewage) and effluent waste water treatment plant (WWPT) and receiving waters.

The results show that the average counts of ESBL producing Enterobacteriaceae in hospital sewage were much higher (more than $2.5 \operatorname{logs}$ ) than those observed in urban waste water. On the other hand, the sewage treatment plant studied did not perform well in removing pathogenic microorganisms. Although Enterobacteriaceae concentrations were reduced in the final effluent by almost two log units as compared with the crude sewage concentrations, a high number of Enterobacteriaceae were detected in the effluent, representing a risk for microbiological pollution of water resources. A strong increase in ESBL-producing bacteria in the receiving water was detected after effluent discharge WWPT.

The results obtained have also demonstrated that the hospital sewage releases a high concentration of VRE $\left(>3.0 \times 10^{5} \mathrm{CFU} / 100 \mathrm{ml}\right)$, which represents $25 \%$ of the total population of enterococci presents in these waters. The hospital sewage contains a proportion of VRE 10 times higher in comparison with that detected in the urban sewage. The VRE proportion in the urban sewage was very low $(2.6 \%)$ and constant along the different samplings. In the other hand, sewage discharged from municipal sewage treatment plant effluent also increased the VRE proportion in the river Sar water $(1.5 \%$ of EVR in upstream to $3.8 \%$ downstream from the plant). In conclusion, sewage (particularly hospital sewage) contains a high proportion of ESBL producing Enterobacteriaceae and vancomycin resistant enterococci, implying a potential risk of spreading these
\end{abstract}


resistant bacteria and resistance genes to the environment and possibly to the human and animal population.

Keywords: $\beta$-lactamases, drug resistance, ESBLs, hospital and urban sewage, Enterobacteriaceae, vancomycin-resistant enterococci.

\section{Introduction}

During the last fifty years the utilization of antimicrobial drugs has steadily increased. Antimicrobials are extensively used in human medicine to treat or prevent bacterial infectious diseases. Antimicrobial resistant bacteria and antimicrobial residues are excreted from patients into the hospital wastewater daily [1]. Consequently, the hospital wastewater may be a hot spot for the propagation and dissemination of antimicrobial resistant and pathogenic bacterial isolates. Some reports showed that high resistance rates to several antimicrobial agents are also observed in commensal and environmental bacteria [2, 3]. Thus, the emergence and dissemination of antibiotic resistant bacteria in hospitals and environments is an emerging challenge to humankind.

Strains of Enterobacteriaceae that produce extended-spectrum $\beta$-lactamases have emerged as significant pathogens. First reported in the mid-1980s, they were mainly found in Klebsiella pneumoniae and Escherichia coli, although they can now be found in many other species [4]. The emergence of multiresistance in the Enterobacteriaceae family is a question that needs attention, because these are important causative agents of hospital infections, typically associated with pneumonias, blood stream infections, urinary tract infections, bacteremia and other intra-abdominal infections [5-8]. Reports of infection or colonization with ESBL-producing Enterobacteriaceae strains have focused mainly on hospitalized patients or nursing home residents [4]. However, ESBL-producing Enterobacteriaceae have also been described in animals and in patients in the community, with and without chronic conditions [9, 10]. Additionally, studies have demonstrated the ESBL-producing bacteria are isolated with increasing frequency in many parts of the world [7, 11-17].

Although many resistant bacteria have been isolated from environmental samples, there are only limited studies that have addressed the detection of ESBL-producing bacteria from these types of samples [18, 19]. Prado et al [19] observed the presence of Klebsiella pneumoniae producing ESBL in the effluent and sludge of hospital sewage plants. Therefore, the hospital sewage or the low efficacy of hospital sewage-treatment plants could result in the dissemination of ESBL-producing bacteria. In addition, it is generally accepted that waste water treatment plants play an important role in redistributing and disseminating antimicrobial resistance properties to bacteria. In fact, the almost permanent presence of detectable antimicrobial levels in the waters of waste water treatment plants could strongly influence the environment, creating a selective pressure that would be ultimately responsible for the dominance of populations of resistant microorganisms among those present in the habitat.

Although it was investigated the presence of ESBL-producing bacteria in hospital sewage and environmental samples, we lack data on the quantitative 
importance of these bacteria in these environments, consequently the aim of this study was to quantify ESBL-producing Enterobacteriaceae, present in the inflow (hospital and urban sewage) and effluent waste water treatment plant (WWPT) and receiving waters.

By the other hand, enterococci have emerged as one of the clinical challenges when identified as the cause of serious or life threatening infections. Isolates of Enterococcus faecalis and Enterococcus faecium are the third- to fourth-most prevalent nosocomial pathogen worldwide [20]. Antimicrobial resistance in strains causing nosocomial infections is a growing problem and VRE in particular are considered a serious threat in hospitals around the world [21]. Vancomycin is often used as a last resort in treatment of antibiotic resistant gram-positive bacterial infections caused by organisms such as multi-resistant enterococci and methicillin resistant staphylococci. Infections due to VRE are associated with higher treatment costs, prolonged morbidity, and greater mortality rates [22].

In the USA, the prevalence of VRE is mainly documented as nosocomial infection in humans $[23,24]$. The situation regarding VRE in Europe is diverse with prevalences ranging from $<1$ to $>40 \%$ and many aspects of VRE acquisition and spread are still unknown [20]. In any case, acquired vancomycin resistance appears to be a serious and growing therapeutic challenge among enterococci all over Europe. According Werner et al [20], some EU countries have experienced an increasing VRE trend over time (e.g., Ireland, Germany, Greece); in other countries VRE prevalence is still low (e.g., in Nordic countries, the Netherlands); a few EU Member States showed decreasing VRE rates (e.g., Austria, Portugal, Italy).

The spread of these organisms from the hospital environment or other sources to environmental waters through discharged sewage or other means could increase the prevalence of these strains in the human population and become a potential risk to human health [25-27]. Several studies have detected VRE strains in hospital-impacted sewage [26, 28], sewage [29] and in receiving waters [28].

The second aim of the present study was to assess the number of vancomycinresistant enterococci present in the hospital sewage and receiving waters.

\section{Materials and methods}

\subsection{Water samples collection}

Samples were collected from sewage effluent University Hospital of Santiago de Compostela (Spain), both wastewater and municipal sewage treatment plant of Santiago de Compostela, River Sar (upstream and downstream of sewage treatment plant discharge, sampling sites 1, 2 and 3, respectively) and estuary of Arousa (sampling site 4, shellfish cultivation area). Site 1, is at 0,2 $\mathrm{Km}$ upstream of WWPT, site 2 is at $7 \mathrm{Km}$ downstream of WWPT and site 3 is at $15 \mathrm{Km}$ downstream of WWPT.

Sampling was carried out in April 2004, September 2004, February 2005 and June 2005 , over 2 weeks in each month. Wastewater and water samples were 
collected into sterile bottles. The wastewater samples were collected during a $24 \mathrm{~h}$ period, harvesting $50 \mathrm{ml}$ every $60 \mathrm{~min}$, refrigerated and analysed within $24 \mathrm{~h}$.

\subsection{Isolation and enumeration of Enterobacteriaceae}

The Enterobacteriaceae count from waste water samples were obtained by inoculating one $\mathrm{ml}$ aliquots of the appropriate dilution in chromogenic Coli-ID agar (supplied by bioMerieux, France). All plates were incubated aerobically for $24 \pm 2 \mathrm{~h}$ at $36.0 \pm 1.0^{\circ} \mathrm{C}$. All pink/violet and blue/grey colonies on Coli-ID agar were counted as presumptive Enterobacteriaceae. Typical colonies were picked off for confirmation as Enterobacteriaceae based on the following tests: Gram stain, oxidase and glucose fermentation [30].

The Enterobacteriaceae count from River Sar and estuary of Arousa were analysed by standard membrane filtration technique, using the same culture media and incubation conditions.

The same methods were employed for ESBL-producing Enterobacteriaceae counts, supplementing Coli-ID agar with $2 \mu \mathrm{g} / \mathrm{ml}$ of ceftazidime, cefotaxime, ceftriaxone and aztreonam. Confirmation of $\beta$-lactamase production by strains isolated from agar supplemented Coli-ID was carried out using the test specified by Steward et al [31].

\subsection{Isolation and enumeration of enterococci}

At the laboratory, wastewater samples $(0.1 \mathrm{ml}$ aliquots of the appropriate dilution) were directly streaked onto Slanetz \& Bartley Medium for enterococci count. Water samples from River Sar and estuary of Arousa were analysed by membrane filter technique [32]. VRE were isolated on M-enterococcus containing $32 \mu \mathrm{g} / \mathrm{ml}$ vancomycin and were incubated for $48 \pm 3 \mathrm{~h}$ at $36.0 \pm$ $1.0^{\circ} \mathrm{C}$.

\section{Results and discussion}

The average counts of Enterobacteriaceae and ESBL-producing Enterobacteriaceae obtained from all wastewater samples (hospital and urban sewage, influent and effluent WWPT) collected throughout the study are shown in Figure 1. The results show that among the urban and hospital sewage there is little difference in the total level of enterobacteria. On the contrary, it is noteworthy that the average counts of ESBL producing Enterobacteriaceae in hospital sewage were much higher (more than 2.5 logs) than those observed in urban wastewater. This clearly highlights the importance of hospital sewage as a major source of antibiotic-resistant bacteria.

One of the recurring concerns because of the presence of ESBL-producing bacteria in these environments is associated with the transfer of conjugative plasmids, which also carry genes of resistance to aminoglucosides and sulfonamides, giving the bacteria multiresistance patterns [33]. Conjugative plasmids can be easily transferred to other bacteria $[34,35]$. This mechanism of 
gene transfer is particularly important in hospital effluents, because in such environments, the possibility of gene exchange is increased as a result of higher density and greater contact between these microorganisms, which allows for an increased rate of horizontal transfer of these genes.

The incorrect handling and disposal of the hospital sewage into inappropriate locations may compromise public health by contaminating the soil, water supplies or recreational waters, and facilitate dissemination of microorganisms and resistance genes into the environment. In this way, a high prevalence of resistant micro-organisms in hospitals shows a potential risk for disseminating pathogenic agents into the environment, particularly through the wastewaters.

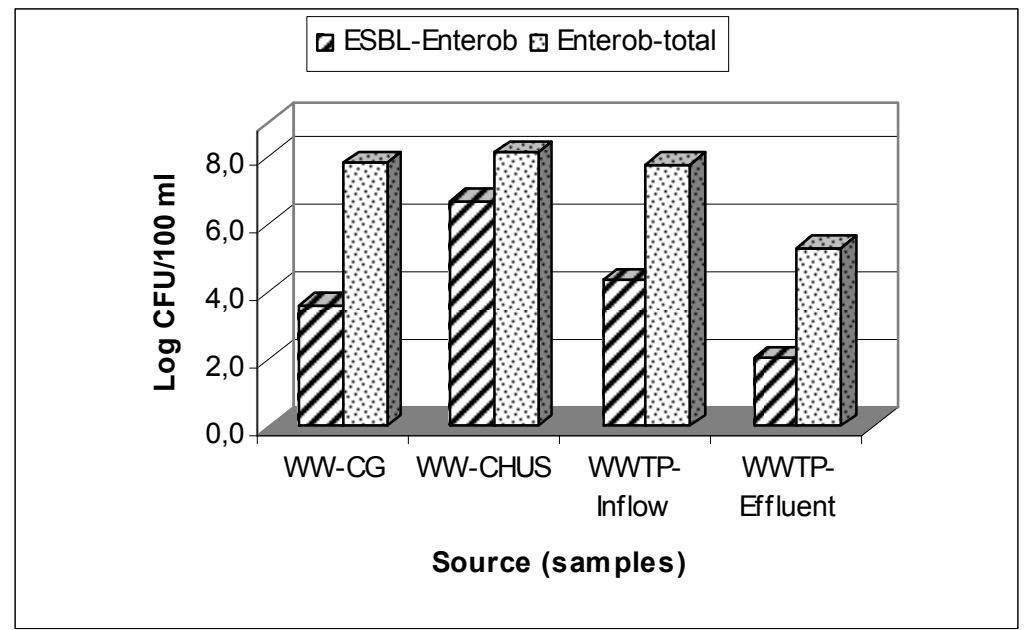

Figure 1: Average counts of Enterobacteriaceae and ESBL producing Enterobacteriaceae obtained from the water samples. WW-CG, waste water general collector of Santiago de Compostela. WW-CHUS, waste water from University hospital complex of Santiago de Compostela. WWTP, waste water treatment plant.

By the other hand, the sewage treatment plant studied did not perform well in removing pathogenic micro-organisms. Although Enterobacteriaceae concentrations were reduced in the final effluent by almost two log units as compared with the crude sewage concentrations, a high number of Enterobacteriaceae were detected in the effluent, representing a risk for microbiological pollution of water resources. Thus, as shown in Figure 2, the wastewater discharge from WWTP causes a strong increase in ESBL-producing bacteria in the receiving waters, so that $15 \mathrm{~km}$ downstream of discharge point, is still detected a high level of resistant bacteria. In Figure 2, also notes the presence of ESBL-producing bacteria in the water of shellfish cultivation area affected by the river waters at that WWTP discharged wastewater. Thus, the prevalence of ESBL-producing Enterobacteriaceae was notable in all the environments studied, suggesting a global expansion of these enzymes, as recorded Mesa et al [18]. 


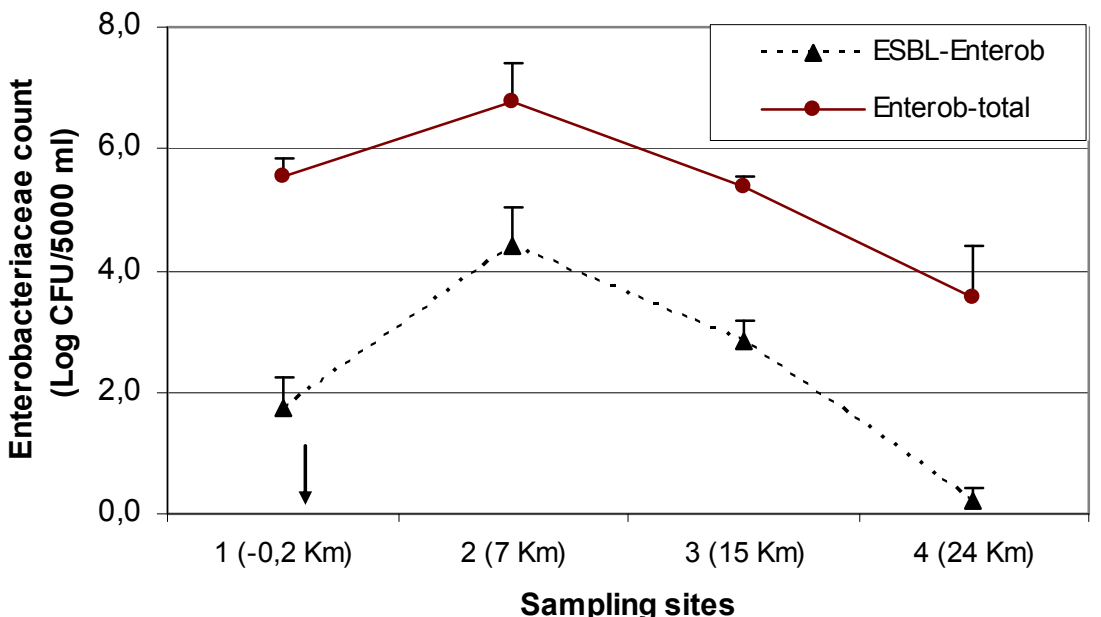

Figure 2: Enterobacteriaceae (Enterob-total) and ESBL producing Enterobacteriaceae (ESBL-Enterob) counts in four sampling sites along the river Sar. Values shown are geometric means of six determinations. The arrow indicates the dumping site of treatment plant into the river.

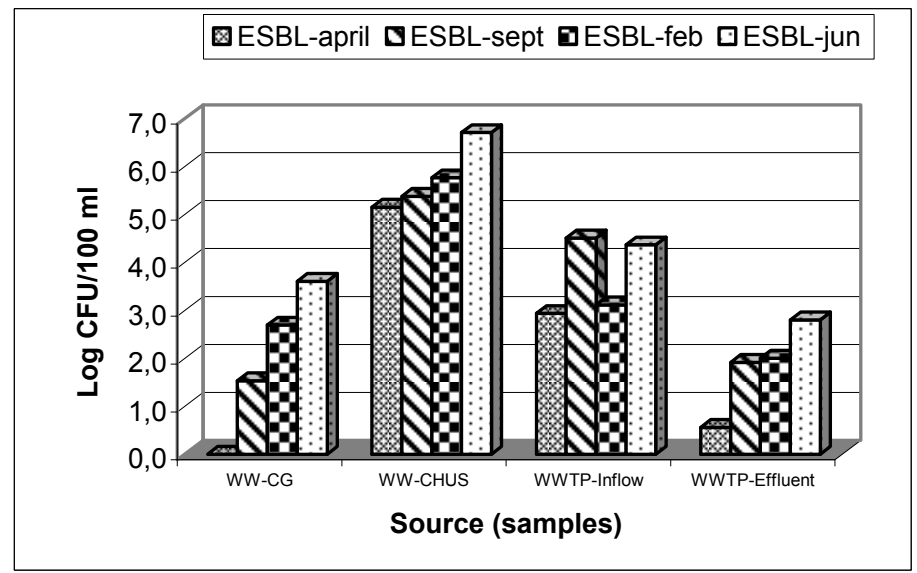

Figure 3: ESBL-producing Enterobacteriaceae (ESBL) counts obtained in water samples collected in April, September (sept), February (feb) and June (jun). WW-CG, waste water general collector of Santiago de Compostela. WW-CHUS, waste water from University hospital complex of Santiago de Compostela. WWTP, waste water treatment plant. 
When analyzing the results is done taking into account the time of year, Figure 3 shows that the release of ESBL-producing Enterobacteriaceae from hospital waste water was very high throughout the year, particularly in the period of time for June. This same behaviour was observed in waste after samples collected in the other three points. A temporal distribution of ESBL-producing Enterobacteriaceae was also observed by Mesa et al [18] in Spain, who found a higher prevalence between July and November and lowest between February and May.

The results obtained have demonstrated that the hospital sewage also release a high concentration of VRE (>3.0 x $\left.10^{5} \mathrm{CFU} / 100 \mathrm{ml}\right)$, which represents $25 \%$ of the total population of enterococci presents in these waters (Figure 4). The hospital sewage contains a proportion 10 times higher of VRE in comparison with the one that was detected in the urban sewage. In Figure 4 also may be observed that the proportion of VRE was very similar in influent and effluent of the waste water treatment plant.

The VRE proportion compared to the total population of Enterococci in the hospital wastewater throughout the year ranged between 37.05\% in April and $17.6 \%$ in February. Nevertheless, the median values were constant along year (Figure 5). The VRE proportion in the urban sewage was very low (2.6\%) and constant along the different samplings. In the other hand, sewage discharged from municipal sewage treatment plant effluent increased the VRE proportion in the river Sar water $1.5 \%$ of EVR in upstream to $3.8 \%$ downstream from the plant). The results obtained shown that the presence of VRE in environment aquatic is clearly influenced by hospital sewage, which are led to municipal treatment plants and mixed with urban sewage (Figure 6).

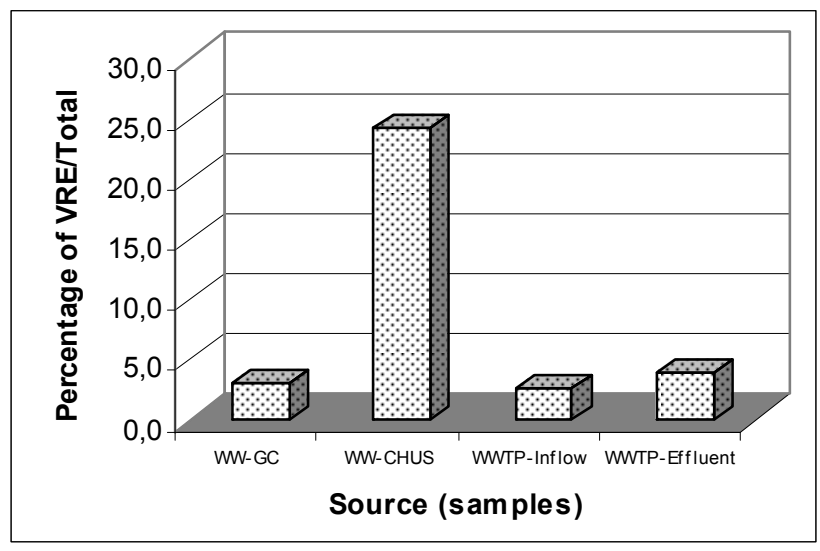

Figure 4: Proportion of vancomycin-resistant Enterococci (VRE) compared to the total population of Enterococci obtained in the water samples. WW-CG, waste water general collector of Santiago de Compostela. WW-CHUS, waste water from University hospital complex of Santiago de Compostela. WWTP, waste water treatment plant. 


\section{圈 VRE-april $\mathbf{\nabla}$ VRE-sept $\mathbf{\nabla}$ VRE-feb $\square$ VRE-jun}

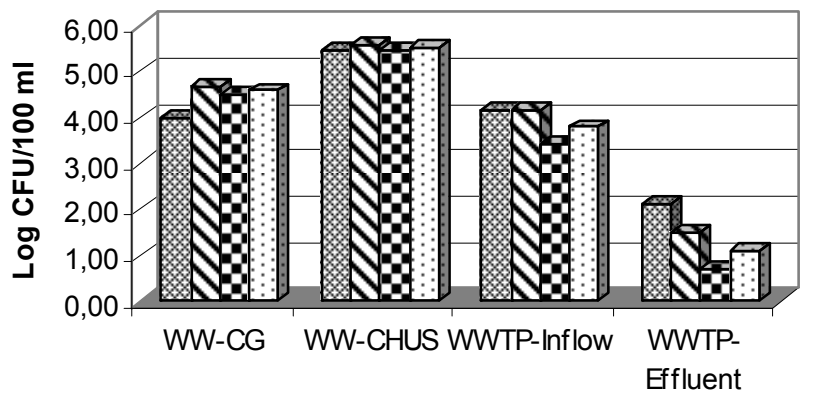

Source (samples)

Figure 5: Vancomycin-resistant Enterococci (VRE) counts obtained in water samples collected in April, September (sept), February (feb) and June (jun). WW-CG, waste water general collector of Santiago de Compostela. WW-CHUS, waste water from University Hospital Complex of Santiago de Compostela. WWTP, waste water treatment plant.

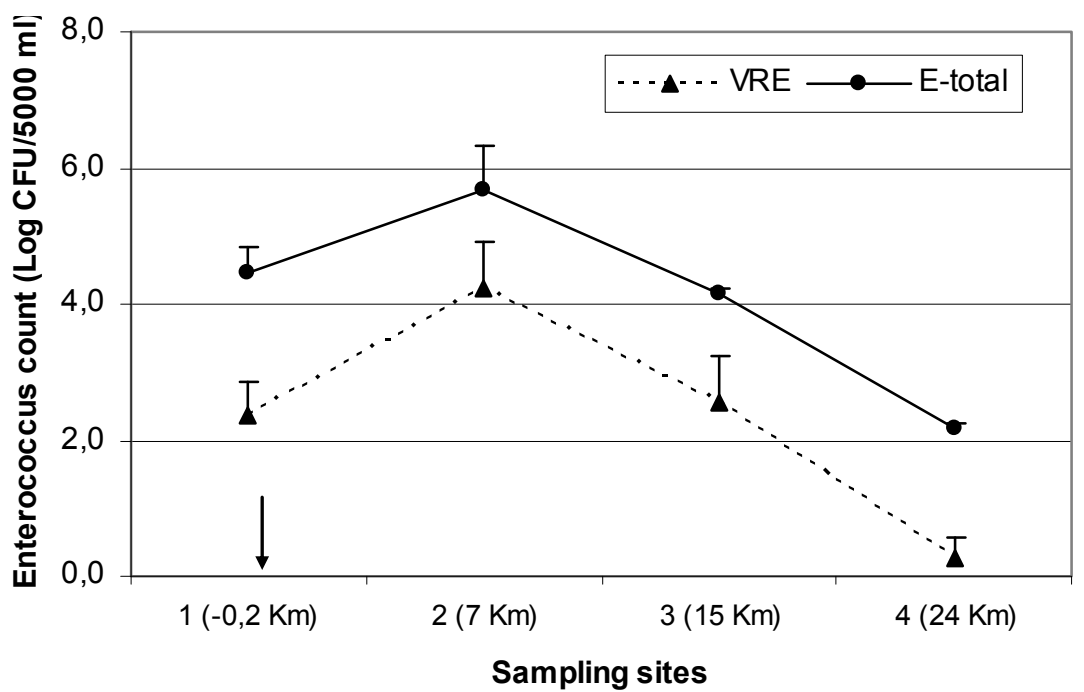

Figure 6: Vancomycin-resistant enterococci (VRE) and total enterococci (E-total) counts in four sampling sites along the river Sar. Values shown are geometric means of six determinations. The arrow indicates the dumping site of treatment plant into the river. 
In conclusion, sewage (particularly, sewage hospital) contains a high proportion of ESBL-producing Enterobacteriaceae and vancomycin resistant enterococci, implying a potential risk of spreading these resistant bacteria and resistance genes to the environment and possibly to the human and animal population. The high incidence of resistant bacteria in sewage implies a need for high efficient hygienic treatment of sewage (application of final disinfection processes for to reduce the microbial burden), with the intention of minimizing the impact from the release of hospital wastewaters into water resources, preventing dissemination of multiresistant microorganisms and their genes of resistance into the environment, thus promoting prevention measures to protect public health.

\section{Acknowledgement}

The work was financially supported by a grant from the Xunta de Galicia (PGIDIT03TAM03E).

\section{References}

[1] Kummerer, A. \& Henninger, K. Promoting resistance by the emission of antibiotics from hospitals and households into effluent. Clin. Microbiol. Infect., 9, pp. 1203-1214, 2003.

[2] Kümmerer, K. Resistance in the environment. J. Antimicrob. Chemother., 54, pp. 311-320, 2004.

[3] Bartoloni, A., Pallecchi, L., Benedetti, M., Fernandez, C., Vallejos, Y., Guzman, E., Villagran, A.L., Mantella, A., Lucchetti, C., Bartalesi, F., Strohmeyer, M., Bechini, A., Gamboa, H., Rodríguez, H., Falkenberg, T., Kronvall, G., Gotuzzo, E., Paradisi, F. \& Rossolini, G.M. Multidrugresistant commensal Escherichia coli in children, Peru and Bolivia. Emerg. Infect. Dis., 12, pp. 907-913, 2006.

[4] Bradford, PA. Extended-spectrum b-lactamases in the $21^{\text {st }}$ century: characterization, epidemiology, and detection of this important resistance threat. Clin. Microbiol. Rev., 14, 933-51, 2001.

[5] Kotapati, S., Kuti, J.L. and Nightingale, C.H. Clinical implications of extended spectrum b-lactamase (ESBL) producing Klebsiella species and Escherichia coli on cefepime effectiveness. J. Infect., 51, pp. 211-217, 2005.

[6] Lopes, A.C.S., Rodrigues, J.F. \& Morais Junior, M.A. Molecular typing of Klebsiella pneumoniae isolates from public hospitals in Recife, Brazil. Microbiol Res., 160, pp. 37-46, 2005.

[7] Grover, S.S., Sharma, M., Chattopadhya, D., Kapoor, H., Pasha, S.T. \& Singh, G. Phenotypic and genotypic detection of ESBL mediated cephalosporin resistance in Klebsiella pneumoniae: emergence of high resistance against cefepime, the fourth generation cephalosporin. $J$. Infect., 53, pp. 279-288, 2006. 
[8] Sun, H.Y., Chen, S.Y., Chang, S.C., Pan, S.C., Su, C.P. \& Chen, Y.C. Community-onset Escherichia coli and Klebsiella pneumoniae bacteremia: influence of health care exposure on antimicrobial susceptibility. Diagn Microbiol. Infect. Dis., 55, pp. 135-141, 2006.

[9] Briñas, L., Moreno, M.A., Teshager, T., Sáenz, Y., Porrero, M.C., Domínguez, L. \& Torres, C. Monitoring and characterization of extendedspectrum b-lactamases in Escherichia coli strains from healthy and sick animals in Spain in 2003. Antimicrob. Agents Chemother., 49, pp. 1262-4, 2005.

[10] Mirelis, B., Navarro, F., Miró, E., Mesa, R.J., Coll, P. \& Prats, G. Community transmission of extended-spectrum b-lactamase. Emerg. Infect. Dis., 9, pp. 1024-1035, 2003.

[11] Peña, C., Pujol, M., Ricart, A., Ardanuy, C., Ayats, J., Liñares, J., Garrigosa, F., Ariza, J. \& Gudiol, F. Risk factors for faecal carriage of Klebsiella pneumoniae producing extended spectrum b-lactamase (ESBL KP) in the intensive care unit. J. Hosp. Infect., 35, pp. 9-16, 1997.

[12] Araque, M., Nieves, B., Lauretti, L. \& Rossolini, G.M. Molecular basis of extended-spectrum b-lactamase production in nosocomial isolates of Klebsiella pneumoniae from Mérida, Venezuela. Int. J. Antimicrob. Agents 15, pp. 37-42, 2000.

[13] Seid, J. \& Asrat, D. Occurrence of extended spectrum b-lactamase enzymes in clinical isolates of Klebsiella species from Harar region, eastern Ethiopia. Acta Trop., 95, pp. 143-148, 2005.

[14] Kolar, M., Latal, T., Cermak, P., Bartonikova, N., Chmelarova, E., Sauer, P. \& Kesselova, M. Prevalence of extended-spectrum b-lactamase-positive Klebsiella pneumoniae isolates in the Czech Republic. Int. J. Antimicrob. Agents, 28, pp. 49-53, 2006.

[15] Lee, H., Yong, D., Yum, J.H., Roh, K.L.H., Lee, K.L., Yamane, K.L., Arakawa, Y. and Chong, Y. Dissemination of $16 \mathrm{~S}$ rRNA methylasmediated highly amikacin-resistant of Klebsiella pneumoniae and Acinetobacter baumannii in Korea. Diagn. Microbiol. Infect. Dis., 56, pp. 305-312, 2006.

[16] Paterson, D.L. Resistance in gram-negative bacteria: Enterobacteriaceae. Am. J. Med., 119, S20-S28, 2006.

[17] Yu, Y., Ji, S., Chen, Y., Zhou, W., Wei, Z., Li, L. \& Ma, Y. Resistance of strains producing extended-spectrum b-lactamases and genotype distribution in China. J. Infect., 54, pp. 53-57, 2006.

[18] Mesa, R.J., Blanc, V., Blanch, A.R., Cortés, P., González, J.J., Lavilla, S., Miró, E., Muniesa, M., Saco, M., Tórtola, M.T., Mirelis, B., Coll, P., Llagostera, M., Prats, G. \& Navarro, F. Extended-spectrum b-lactamaseproducing Enterobacteriaceae in different environments (humans, food, animal farms and sewage). J. Antimicrob. Chemother., 58(1), pp. 211-5, 2006.

[19] Prado, T., Pereira, W.C., Silva, D.M., Seki, L.M., Carvalho, A.P. \& Asensi, M.D. Detection of extended-spectrum beta-lactamase-producing Klebsiella 
pneumoniae in effluents and sludge of a hospital sewage treatment plant. Lett. Appl. Microbiol., 46(1), 136-41, 2008.

[20] Werner, G., Coque, T.M., Hammerum, A.M., Hope, R., Hryniewicz, W., Johnson, A., Klare, I., Kristinsson, K.G., Leclercq, R., Lester, C.H., Lillie, M., Novais, C., Olsson-Liljequist, B., Peixe, L.V., Sadowy, E., Simonsen, G.S., Top, J., Vuopio-Varkila, J., Willems, R.J., Witte, W. \& Woodford, N. Emergence and spread of vancomycin resistance among enterococci in Europe. Euro Surveill., 13(47), pp. 1-11, 2008.

[21] Mascini, E.M., Bonten, M.J. Vancomycin-resistant enterococci: consequences for therapy and infection control. Clin. Microbiol. Infect., 11(Suppl 4), pp. 43-56, 2005.

[22] Calfee, D.P., Giannetta, E.T., Durbin, L.J., Germanson, T.P. \& Farr, B.M. Control of endemic vancomycin-resistant Enterococcus among inpatients at a university hospital. Clin. Infect. Dis., 37, pp. 326-332, 2003.

[23] Bonten, M.J., Willems, R. \& Weinstein, R.A. Vancomycin-resistant enterococci: why are they here, and where do they come from? Lancet Inf. Dis., 1, pp. 314-325, 2001.

[24] Coque, T.M., Tomayko, J.F., Ricke, S.C., Okhyusen, P.C. \& Murray, B.E. Vancomycin-resistant enterococci from nosocomial, community, and animal sources in the United States. Antimicrob. Agents Chemother., 40(11), pp. 2605-2609, 1996.

[25] Rice, E.W., Messer, J.W., Johnson, C.H. and Reasoner, D.J. Occurrence of high-level aminoglycoside resistance in environmental isolates of enterococci. Appl. Environ. Microbiol., 61, 374-376, 1995.

[26] Iversen, A., Kühn, I., Franklin, A. \& Möllby, R. High prevalence of vancomycin-resistant enterococci in Swedish sewage. Appl. Environ Microbiol., 68, pp. 2838-2842, 2002.

[27] Kühn, I., Iversen, A., Finn, M., Greko, C., Burman, L., Blanch, A., Vilanova, X., Manero, A., Taylor, H., Caplin, J., Domínguez, L., Herrero, I., Moreno, M.A. \& Möllby, R. Occurrence and Relatedness of Vancomycin-Resistant Enterococci in Animals, Humans, and the Environment in Different European Regions. Appl. Environ. Microbiol., 71(9), pp. 5383-5390, 2005.

[28] Novais, C., Coque, T.M., Ferreira, H., Sousa, J.C. \& Peixe, L. Environmental contamination with vancomycinresistant enterococci from hospital sewage in Portugal. Appl. Environ. Microbiol., 71, pp. 3364-3368, 2005.

[29] Poole, T.L., Hume, M.E., Campbell, L.D., Scott, H.M., Alali, W.Q. \& Harvey, R.B. Vancomycin-resistant Enterococcus faecium strains isolated from community wastewater from a semiclosed agri-food system in Texas. Antimicrob. Agents Chemother., 49, pp. 4382-4385, 2005.

[30] ISO 21528-2:2004. Microbiology of food and animal feeding stuffs -Horizontal methods for the detection and enumeration of Enterobacteriaceae -- Part 2: Colony-count method.

[31] Steward, C.D., Rasheed, J.K., Hubert, S.K., Biddle, J.W., Raney, P.M., Anderson, G.J., Williams, P.P., Brittain, K.L., Oliver, A., McGowan, J.E. 
$\mathrm{Jr}$, \& Tenover, F.C. Characterization of clinical isolates of Klebsiella pneumoniae from 19 laboratories using the National Committee for Clinical Laboratory Standards extended-spectrum $\beta$-lactamase detection methods. J. Clin. Microbiol., 39, pp. 2864-2872, 2001.

[32] Norma ISO 7899-2:2000. Water quality -- Detection and enumeration of intestinal enterococci -- Part 2: Membrane filtration method.

[33] Paterson, D.L. (2006) Resistance in gram-negative bacteria: Enterobacteriaceae. Am. J. Med. 119, pp. S20-S28, 2006.

[34] Heuer, H., Krogerrecklenfort, E., Wellington, E.M.H., Egan, S., Van Elsas, J.D., Van Overbeek, L., Collard, J.M. \& Guillaume, G. Gentamicin resistance genes in environmental bacteria: prevalence and transfer. FEMS Microbiol. Ecol., 42, pp. 289-302, 2002.

[35] Tennstedt, T., Szczepanowski, R., Braun, S., Pühler, A \& Schlüter, A. Occurrence of integron-associated resistance gene cassetes located on antibiotic resistance plasmids isolated from a wastewater treatment plant. FEMS Microbiol. Ecol., 45, pp. 239-252, 2003. 